\title{
Recruitment and Development of Academic Pediatricians: Departmental Commitments to Promote Success
}

\author{
ALAN H. JOBE, JON S. ABRAMSON, MARK BATSHAW, LAURENCE A. BOXER, \\ GEORGE LISTER, EDWARD McCABE, AND RICHARD JOHNSTON, FOR THE WORK GROUP ON \\ RESEARCH OF THE AMERICAN PEDIATRIC SOCIETY \\ Children's Hospital, Cincinnati, Ohio, U.S.A. [A.H.J.]; Wake Forrest University, Winston Salem, North \\ Carolina, U.S.A. [J.S.A.]; Children's National Medical Center, Washington, D.C., U.S.A. [M.B.]; \\ University of Michigan, Ann Arbor, Michigan, U.S.A. [L.A.B.]; Yale University, New Haven, Connecticut, \\ U.S.A. [G.L.]; University of California Los Angeles, Los Angeles, California, U.S.A. [E.M.]; University of \\ Colorado, Denver, Colorado, U.S.A. [R.J.]
}

The general consensus, supported by the report of the Future of Pediatric Education II, is that the number of pediatricianscientists is critically low $(1,2)$. This acute manpower shortage is occurring simultaneously with the competing needs for pediatrician-educators to teach the next generation of pediatricians and for subspecialist pediatricians to provide care for the increased referrals of children for complex subspeciality care (3). Although the number of pediatricians entering subspeciality training increased to $23 \%$ of the candidates taking the pediatrics certifying exam in 2000 (4), the subspeciality trainees who will become successful pediatrician-scientists of the future are a small minority of the total. These individuals will be the core pediatric investigators who will sustain innovative research related to child health. The few well-prepared subspecialists leaving training programs each year are heavily recruited and should be viewed as a precious resource for academic pediatrics. Their careers should not be put at risk by their accepting jobs without departmental commitments to optimize their chances to succeed in academic pediatrics at the highest level. This discussion focuses on the department resources that need to be provided to develop successful academic pediatricians, whether they engage in basic, clinical, or health services research.

\section{MENTORING}

The talented faculty candidate with an M.D., M.D./M.P.H., or M.D./Ph.D. degree will need an environment mentored for intellectual and scientific growth, which should be crafted during the recruitment process (5). Mentoring may be a team

Received October, 2001; accepted November 8, 2001.

Correspondence: Alan Jobe, M.D., Ph.D., Children's Hospital Medical Center, Division of Pulmonary Biology, 3333 Burnet Avenue, Cincinnati, OH 45229-3039, U.S.A.; e-mail: jobea0@chmcc.org

R.J. served as liaison to the American Pediatric Society. effort that includes an established investigator, daily interactions with other investigators at different career levels, and association with a research group with common interests. Mentoring should provide career guidelines, give critical feedback, and stimulate collaborative activities. Research today requires the collaborative use of techniques, equipment, and resources. However, the young investigator also needs intellectual space to develop independence within a supportive environment. Mentorship to advise and encourage the young investigator is the most critical component of the research environment.

\section{INITIAL FINANCIAL RESOURCES FOR THE LABORATORY INVESTIGATOR}

The financial commitments for recruitment of a laboratorybased young investigator are considerable and generally underestimated. The costs of the initial recruitment package to the recruiting department will depend on the source of the salary and available laboratory resources. We sent surveys to the chairs of the 20 departments of pediatrics and the three children's hospitals with the highest amounts of research funding from the National Institutes of Health to estimate the resources used by these departments to recruit and develop new academic faculty. We received responses from 20 institutions, and the average costs and periods of support are given in Table 1. The financial commitment to develop a laboratory investigator based on the average estimates is about $\$ 650,000$ for the initial $3 \mathrm{y}$ of support. The average research space needs are estimated to be $540 \mathrm{sq}$. $\mathrm{ft}$. in addition to an office. Optimally, this research space will be contiguous to the laboratories of the primary research mentors. One institution provides only shared space with the mentors.

Initial costs may be lower if the recruitment is into a well-funded laboratory. Costs could be higher depending on 
Table 1. Costs of supporting initial academic careers

\begin{tabular}{|c|c|c|c|}
\hline & \multicolumn{3}{|c|}{ Faculty Description } \\
\hline & $\begin{array}{c}\mathrm{MD} \text { or } \mathrm{MD} / \mathrm{PhD} \\
\text { laboratory investigator }\end{array}$ & $\begin{array}{l}\text { MD clinical/epidemiology } \\
\text { research }\end{array}$ & MD clinician/teacher \\
\hline \multicolumn{4}{|l|}{ Salary + fringe benefits } \\
\hline Yearly (dollars $\times 1000)$ & $120 \pm 20(80-200)$ & $124 \pm 18(100-150)$ & $128 \pm 20(90-160)$ \\
\hline Period of full salary support (years) & $3.1 \pm 0.6(1-5)$ & $3.1 \pm 0.8(1-5)$ & - \\
\hline Initial equipment costs (dollars $\times 1000)$ & $97 \pm 73(0-400)$ & $35 \pm 29(0-150)$ & - \\
\hline Period of support (years) & $3.0 \pm 0.5(1-5)$ & $3 \pm 0.7(1-5)$ & - \\
\hline Research space $\left(\mathrm{Ft}^{2}\right)$ & $540 \pm 175(200-1200)^{*}$ & $306 \pm 194(100-1200)$ & - \\
\hline Period to achieve partial extramural salary support (years) & $3.3 \pm 0.7(2-5)$ & $3.3 \pm 0.7(2-5)$ & - \\
\hline
\end{tabular}

All values are averages $\pm \mathrm{SD}$. The range given in parentheses is the highest and lowest provided by the centers.

* One institution provides only shared space.

equipment and other specialized needs. These costs can be defrayed in part by university- or hospital-supported start-up funds, institutional and regional grants, and National Institutes of Health support, such as a K08 grant. However, it is important to recognize the magnitude of the commitment needed to initiate the laboratory career of a young pediatrician with the potential to become an independent investigator. Skimping on supplies or technical support is not prudent, as they are essential for progress.

\section{TIME COMMITMENT}

The young pediatrician with academic aspirations must have protected time to focus on research endeavors. This means protected time from not only clinical duties but also teaching and administration. Research time should be $70-80 \%$ of the work week, realizing that the "work week" is not realistically $40 \mathrm{~h}$. Reasonable guidelines are a half-day clinic once a week and 2 mo of primary attending time or a clinic day and some responsibility for a consult service. Ideally, the clinical activities can be tailored to link as closely as possible to the individuals' research interests. The hope is that linking the laboratory-based research and clinical activities may result in translational research in the future. The young investigator should not have teaching responsibilities outside his or her primary areas of interest. The division should build a fire wall around the young investigator to prevent the creep of clinical and administrative obligations.

\section{DEPARTMENTAL PLANNING}

The young investigator will need mentoring for $2-5 \mathrm{y}$, in the model of the KO8 grant from National Institutes of Health. The department needs to recognize that a young investigator who is succeeding likely will progress from complete departmental support for about 3 y through institutional, regional, and foundation support to the RO1 grant over 3 to $5 \mathrm{y}$. This progression will require departmental resources for more than the first $3 \mathrm{y}$ of a faculty appointment to optimize the chances of success. Assuming that $50 \%$ of individuals recruited for such career development will become independent investigators, the departmental financial commitment to develop one investigator will be $\$ 1.5$ million or more (two individuals at $\$ 650,000$ plus support beyond $3 \mathrm{y}$ ). Departments of pediatrics should not recruit motivated pediatric specialists to develop laboratorybased research careers unless they have the resources, the mentors, and the patience to support and nurture this activity. These individuals are among the most valuable resources in pediatrics, whose opportunities for success should be optimized by a high-quality environment.

One strategy for developing the research activity within a division is to retain the excellent fellow as a junior faculty member. This individual, if of high quality, also will be aggressively recruited by other institutions. The division electing to hire a fellow for development as an independent investigator needs to construct a career development program equivalent to that for the outside recruit. The retention of a fellow should not be viewed as a cheap recruit requiring fewer divisional obligations, less start-up support, or less protected time. Ideally, the fellow will receive specialized training outside the division and will return with unique skills and perspective, which increase the research scope and capacity of the division. This young investigator also needs structured mentoring, but an extra emphasis needs to be made to develop the independence and true collaborative opportunities for the individual. If the new hire is dependent solely on his or her previous advisor, academic advancement will be problematic.

\section{RESOURCES FOR CLINICAL INVESTIGATORS}

The needs of the young investigator interested in epidemiology/outcomes research are somewhat different. This individual requires postgraduate training at a level comparable to an M.P.H. or Ph.D. that is programmed into the fellowship or early faculty years. The development of databases or clinical studies may require more time to achieve a publication record than for the laboratory-based investigator. This extra degree work and the time to become productive may require imaginative approaches to the academic title and appropriate salary support to avoid the "academic clock" from interrupting a promising career. The need for a structured mentorship and protected time are as essential as for the laboratory-based investigator. Departments of pediatrics need to use schools of public health and independent institutions such as the RAND Corporation to help develop rich, mentored environments with 
the resources essential for career development. Recruitment costs may be less because of shared resources, but the young clinical epidemiologist or health services researcher also will need support personnel, equipment, space, and protected time to succeed. Estimates from the department chairs are similar to those for the lab-based investigator, except for lower initial costs to establish the laboratory and lower space requirements (Table).

\section{RECRUITMENT OF NONCLINICIAN INVESTIGATORS}

Another strategy for developing research within a department of pediatrics is to recruit Ph.D. scientists to faculty positions. There are institution-specific rules regarding tenure and advancement opportunities for Ph.D. scientists within clinical departments. In some institutions, the Ph.D. serves primarily as a support person without the prospect of institutional salary support. For Ph.D. faculty with the potential for becoming independent investigators, this support role should be adjusted to allow development of self-supported independence. When Ph.D. faculty are recruited to clinical departments, their chances of success and stature within an institution will be improved if they are co-recruited with basic science departments; this will give them a scientific home that assures access to the resources and graduate students in the basic science department. This arrangement ultimately will strengthen the research infrastructure of the pediatrics department. Just as for the clinician-scientist, the Ph.D. recruit will need space, salary, equipment, technical support, and supply money to initiate a research program, requiring a significant commitment from the division/department. Mentoring is equally important, and this should be done as a joint activity of the clinical and basic science departments.

\section{CLINICIAN EDUCATORS}

Realistically, only a minority of subspecialist trainees are sufficiently motivated and well trained to succeed as academic investigators. Clinical programs desperately need subspecialists to manage the growing numbers of subspecialty referrals in pediatrics (3). Depending on the institution, there are numerous variations of "clinical tracks," and these often require some academic activity to maintain a clinical title. These specialist pediatricians are the flip side of the $80 \%$ investigator and may have only $20 \%$ of their time available for creative/academic activities. The goal of recruitment of less research-oriented fellows to clinician/teacher tracks should not simply be patient care. Their $20 \%$ time is a valuable resource that should be structured to develop scholarly activities, unique clinical skills, or superior teaching skills to sustain their motivation and enthusiasm for subspecialty pediatrics. This can be best accomplished by close mentorship to focus the efforts of these young faculty toward collaborative endeavors that will be personally satisfying. Departmental resources need to be avail- able, perhaps on a competitive basis, to allow these individuals to participate in and to complete focused projects. Educational funds and resources need to be available to allow them to become better clinicians and teachers. A very few will move from a clinical academic track to a research track, and a considerable number initially on the research track will become clinician/educators. Faculty who move from the research track to become clinician/educators can contribute to the clinical and teaching mission of the department.

\section{ESTABLISHING INDEPENDENCE}

A mentoring system for faculty development may foster actual or perceived dependence of the young investigator on the mentor. It may be difficult to distinguish the unique accomplishments and directions of the new faculty member from those of the established investigator. It is important to develop some very specific strategies to help make the transition to independence. Areas where this independence can be demonstrated are as follows:

1. Publication. When possible, the young investigator should be the first author and the corresponding author; the young investigator should publish without the mentors.

2. Grant support. Young investigators should seek some independent funding, even if it is only supplemental; if they remain associated with their mentor's research group, they should establish a new area of research; they should strive to write independent grants with their mentor as consultant rather than co-investigator.

3. Interactions outside the research group. Young investigators should actively seek and accept intra- and extramural opportunities to present their research in the absence of their mentors; this will develop communication skills and confidence, independence, and an opportunity for developing collaborations with other investigators.

All subspecialist pediatricians who are performing well in their assigned roles in academic centers need to be valued and rewarded for their successes. Even the most motivated of individuals can lose focus and drive if the responsibilities and expectations placed on them are not concordant with their interests and talents. The challenge for chairpersons and subspecialty section directors is to match opportunities and resources to the interest and potential of the new faculty recruit.

\section{REFERENCES}

1. Gruskin A, Williams RG, McCabe ERB, Stein F, Strickler J 2000 Final report of the FOPE II Pediatric Subspecialists of the Future Workgroup. Pediatrics 106:1224-1244

2. Moskowitz J, Thompson JN 2001 Enhancing the clinical research pipeline: training approaches for a new century. Acad Med 76:307-315

3. Gilchrist G, Fierson W, Spencer CH, Outwater K, Saltzman E, Coran A, White P 2001 The future of pediatric education (FOPE) II report summary and pediatric subspecialists. Pediatrics 107:1179-1180

4. Tunnessen WW, Guerin RO, Stockman JA 2001 Pediatric workforce: data from the American Board of Pediatrics. J Pediatr 139:311-316

5. McCabe LL, McCabe ERB 2000 How to Succeed in Academics. Academic Press, San Diego, pp 23-29 